\title{
A panel discussion
}

\section{Safety in the operating room}

\section{Participants}

Gordon M. Wyant MD, FRCP(C), FFARCS

University of Saskatchewan (Chairman)

Douglas B. Craig MD, FRCP(C)

University of Manitoba (The Anaesthetic

Machine)

Stanley P. Pietak MD, FRCP(C)

Queen's University (The Anaesthetic Ventilator)

Leonard C. Jenkins MD, FRCP(C)

University of British Columbia (The Anaesthetic Monitor)

Arthur J. Dunn MD, FRCP(C)

University of Toronto (The Legal Implications)

\section{Introduction}

Enormous strides have been made in improving the safety of patients during surgical operations. Whereas once upon a time a trip to the operating room was an adventure attended by a significant risk to life, often attributed to the anaesthesia, a fatal

Based on presentations given at the Annual Meeting of the Curadian Anaesthetists' Society in Vancouver, B.C., June 18-22, 1983. outcome from this cause has become a real rarity. However, pari passu with this overwhelming safety record despite ever more complicated operations in increasingly poor risk patients, public expectations and demands for perfection have risen even more dramatically. Also the complexities of modern procedures have raised significantly the chances of non-fatal misadventures related to the administration of an anaesthetic. Hence it is incumbent upon all to consider at least some aspects of the present state of safety in the operating room.

Much attention has been paid in recent years to this subject, at least as far as equipment is concerned, and it is this facet with which these discussions are primarily concemed. There are of course many other factors involved in anaesthetic agents and adjuvant drugs and above all the human factor. This latter will be touched upon in the discussion of the legal implications of operating room safety, but such factors as selection and training of personnel are not being dealt with here.

In keeping with the emphasis on safety of equipment, a collection of standards has been developed, starting with anaesthetic cylinders and pipelines and extending through all components and accessories of the anaesthetic machine right to and including the tracheal tube. This work, under the overall aegis of the Canadian Standards Association, has been eminently successful in eliminating some hazards inherent in equipment of diverse manufacture, especially since the work has been expanded into the international field. However, all standards are voluntary and can become operative only if the consumer-anaesthetist insists on restricting purchases to equipment which conforms to the applicable standard.

With this background in mind each of the authors will explore in some detail problems of safety in their respective fields and suggest improvements where they are indicated. 